\title{
Efficacy of Management Skills Group Training for Mothers on Self-Esteem and Anxiety of Their Children With Attention Deficit and Hyperactivity Disorder
}

\author{
Narguesse Saliminia, ${ }^{1}$ Esmat Danesh, ${ }^{2,}{ }^{*}$ Zahra Hakimi, ${ }^{3}$ and Mina Shamshiri ${ }^{3}$ \\ ${ }^{1}$ Department of Psychology, School of Educational Studies, Universiti Sains Malaysia, Penang, Malaysia \\ ${ }^{2}$ Department of Clinical Psychology, Faculty of Psychology, Karaj Branch, Islamic Azad University, Karaj, IR Iran \\ ${ }^{3}$ Department of Psychology, Karaj Branch, Islamic Azad University, Karaj, IR Iran \\ “Corresponding author: Esmat Danesh, Department of Clinical Psychology, Karaj Branch, Islamic Azad University, Karaj, IR Iran. E-mail: esmat_danesh@yahoo.com
}

Received 2015 January 31; Accepted 2015 July 15.

\begin{abstract}
Background: Attention deficit and hyperactivity disorder (ADHD) has a profound impact on lives of thousands of children and their families. Objectives: Aim of this study was to determine effectiveness of training for mothers, on these children.

Materials and Methods: In this quasi-experimental research, 30 mothers were randomly divided into control and experimental groups and the experimental group received Barkley management skills training in 9 sessions.

Results: Findings showed that anxiety in children of trained mothers was decreased and self-esteem was increased.

Conclusions: The training program for mothers can be an effective method for treatment of psychological disorders in children with ADHD.

Keywords: Anxiety, Attention Deficit, Hyperactivity Disorder, Self Esteem
\end{abstract}

\section{Background}

ADHD is one of the most common behavioral disorders in children. The most important issue is the children's attention and sustained attention [1]. ADHD is accompanied by other problems including low self-esteem and anxietydepression [2]. New findings show that this disorder persists into even adulthood and causes problems in functions [3]. Anxiety is symptom of many psychological disorders. However, self-esteem is the individual attitude towards oneself and self-worth [4]. Family is a social system and any member's dysfunction creates new problems. So, early intervention in the home and school is essential. Although having a child with ADHD is a source of stress, its impact on mothers depends greatly on their cognitive evaluation of the problem, as well as being equipped with the skills to manage the child positively [5]. These mothers apply more authoritarian attitudes [6] and positive parenting program helps them to alleviate this problem [7]. According to Murray Bowen's family systems theory, it is predictable that improper way of interaction with the child intensify biological vulnerability in children with ADHD [8]. On the other hand, the relationships between ADHD, low self-esteem, and high anxiety pose this question that: "Are there any cause and effect relationships among these elements? Or another disorder such as lack of parents' management skills provides low self-esteem and high anxiety?"

\section{Objectives}

This study examined the efficacy of "parent management skill training" on self-esteem and anxiety. Innovation of this study is that maternal education provides a basis for fundamental changes for children with ADHD.

\section{Materials and Methods}

This is a quasi-experimental study with two-month follow-up. The population consisted of 280 mothers of 9 - 11 year-old-children with ADHD who during 2011 to 2013 had referred to the corresponding author's consulting office for treatment. Method of sampling was simple random sampling. Among the 280 mothers, 120 mothers who both themselves and their children had inclusion criteria of the study were listed. Sample were selected randomly (30 mothers) and were arranged in two peer groups of 15 as experimental and control groups. Inclusion criteria of the study were: mothers' education at least at the level of secondary school, having parents living together, parents' physical and mental health, not to be addicted and consumption of the same type and dose of medication; Ritalin by their children. Eliminating criteria of this study were: children with mental retardation, other abnormalities associated with the disorder and to be younger than 9 or older than 11 years old. The instruments were: 1) Coppersmith self-esteem questionnaire. Coopersmith reported 0.88 test-retest reliability coefficient after 
five weeks and 0.70 after three years [9]. Also, other researchers [10] reported Cronbach's alpha; 0.82 for the inventory internal consistency on females at the third grade of secondary school in Khuzestan province (Behbahan). In this research using test-retest reliability coefficient is 0.60 and CSEI (Coppersmith self-esteem inventory) validity has been approved in several researches [10]. Gadow and Spraphkin morbid symptoms questionnaire: Reliability of the inventory was determined through test-retest procedure, and obtained correlation coefficient for teachers was $96 \%$. For parents, the obtained correlation coefficient was $92 \%$. In order to determine the validity of this inventory, content validity and correlation was obtained between the teachers' and parents' data at the first stage which was $89 \%$ and was meaningful [11]. Intervention consisted of Barkley (1995) group program for parents' management skills; mothers of the experimental group received nine educational sessions, once a week, with duration of $90 \mathrm{~min}$ utes. Mothers of the control group did not receive any intervention. The data were analyzed using covariance method. In the present study, parents' management training sessions were held as follow:

- Session one: Included training material. Authentic and clear information about ADHD symptoms were presented to the parents.

- Session two: Four-factor model of child-parent conflicts was described and principles of behavioral management were reviewed.

- Session three: Parents were trained to pay attention positively to children with socially appropriate behavior and not to pay any attention to their inappropriate behavior during "playing a special game."

- Session four: Parents were trained to pay positive attention to the child's appropriate social behavior and neglect inappropriate behaviors in situations that the child is playing independently.

- Session five: Parents learned how to develop a reward system at home and use the points or chips.

- Session six: Parents learned how to take the chips as a punishment when children are not obeying orders and have minor violations of the rules.

- Session seven: The parents were taught how to deprive and use negative reinforcement for a range of wrongdoings including house rules based on insults, aggressiveness and destructiveness.

- Session eight: The parents were taught how to manage behavioral problems of their children in public places and develop some plans to use social reinforcement.

-Session nine: Managing future problems, cooperative working methods with school staffs, and dealing with related problems were discussed. A supportive session after completion of the nine-meeting-program was held after one month to solve parents' problems in continuation of their parenting skills. Data were analyzed through analysis of variance for mixed repeated measures design by SPSS; version 19. The significant level was considered 0.05.

\section{Results}

In terms of the research dependent variables (selfesteem and anxiety) Tables 1 and 2 are presented below to demonstrate the details in the pre-test, post-test and follow-up stages for both groups. Based on the results contained in Table 1, means and standard deviations of selfesteem and anxiety in experimental and control groups' pre-test are almost at the same level. The mean and standard deviation of experimental group's post-test show an increase in self-esteem scores. Two-month follow-up of the experimental and control groups' mean scores represents an increasing continuation of the experimental group's self-esteem. Also, after post-test the means and standard deviations indicate a reduction in anxiety scores in the experimental group. Two-month follow-up scores for the experimental and control groups represent reduction continuity in anxiety scores in the experimental group. Based on the results listed in Table 2, according to the first hypothesis, ADHD children's self-esteem whose mothers were trained in management skills compared with the control group and pre-test increased. Mixed analysis of inter-intra subjects' variance showed a significant interaction between the groups and the stage, partial chi-Ita was 0.903 which implies a significant main effect on time. Ita squared equal to 0.914 , in all of the three periods of time, reflects increasing self-esteem in the experimental group. The main effect comparing the two groups was statistically significant, and the chi-Ita (0.969) represents that the difference between the two groups was extremely high. Therefore, the positive effect of parental management skills training on increasing self-esteem in children with ADHD is confirmed. According to Table 2 on the basis of the second hypothesis, anxiety in children with hyperactivity whose mothers were trained in management skills is reduced compared with the control group and their pretest. The mixed analysis of inter-intra subjects' variance indicates the interaction between the time and the intervention. The squared partial Ita (0.570) shows a significant main effect on time. Ita squared equal to 0.336 , expresses decrease of anxiety in the experimental group in all of the three periods of time. Comparing the two groups, the main effect is significant and chi-Ita (0.687) represents that the difference between the two groups is extremely high. Therefore, the research hypothesis on the effects of parental management skills training in reducing anxiety in children with ADHD is confirmed. 
Table 1. Mean and Standard Deviation of Self-Esteem and Anxiety Scale in Experimental and Control Groups $\left(\mathrm{n}=15\right.$ Subjects in Each Group) ${ }^{\mathrm{a}}$

\begin{tabular}{lccc}
\hline Groups Variable & Pretest & Posttest & Two-Month Follow-Up \\
\hline Self-esteem & & & \\
\multicolumn{1}{c}{ Experimental } & $16.33 \pm 4.22$ & $31.4 \pm 4.59$ & $32.26 \pm 4.96$ \\
\hline Control & $17.20 \pm 3.69$ & $17.73 \pm 4.19$ & $18.13 \pm 4.05$ \\
Anxiety & & & $0.86 \pm 0.91$ \\
\hline Experimental & $3.39 \pm 0.70$ & $1.66 \pm 8.99$ & $4.80 \pm 1.32$ \\
\hline Control & $4.06 \pm 1.90$ & $4.60 \pm 1.35$ & \\
\hline
\end{tabular}

${ }^{\mathrm{a}}$ Values are expessed as mean $\pm \mathrm{SD}$.

Table 2. Mixed ANOVA Analyzing the Effects of Mothers' Education on Their Children Self-Esteem and Anxiety ${ }^{\mathrm{a}}$

\begin{tabular}{|c|c|c|c|c|c|c|c|c|}
\hline \multirow[t]{2}{*}{ Variable } & \multicolumn{4}{|c|}{ Test Within Subjects and Interaction Effects } & \multicolumn{4}{|c|}{ Test Between Subjects and Interaction Effects } \\
\hline & Wilks' Lambda Value & $\mathbf{F}$ & df (Hypothesis and Error) & $\eta^{2}$ & Source of Changes & SS & df & $\mathbf{F}$ \\
\hline \multicolumn{9}{|l|}{ Self-Esteem } \\
\hline Stage & 0.086 & $143.100^{* *}$ & 2 and 27 & 0.914 & Group & 1813.51 & 1 & $36.056^{* *}$ \\
\hline Stage.Group & 0.097 & $125.890^{* *}$ & 2 and 27 & 0.903 & Error & 1408.31 & 28 & \\
\hline \multicolumn{9}{|l|}{ Anxiety } \\
\hline Stage & 0.664 & $6.818^{* *}$ & 2 and 27 & 0.336 & Group & 122.50 & 1 & $61 / 445^{* *}$ \\
\hline Stage.Group & 0.430 & $17.919^{* *}$ & 2 and 27 & 0.570 & Error & 1.994 & 28 & \\
\hline
\end{tabular}

${ }^{\mathrm{a}} \mathrm{P}<0.05 ;{ }^{* *} \mathrm{P}<0.01$

\section{Discussion}

The results of this study approve the effects of parental management skills training on improving self-esteem and reducing anxiety in children with ADHD. It overly showed that the parents' group training program can influence on reducing children's behavioral problems. Reforming the improper educational techniques, sufficient training about this disorder, modifying parenting styles and stress reduction for parents and children justify the obtained results. Managing children with ADHD are much more difficult than children who do not have this disorder and their parents need abundant patience, skills and abilities in their parenting. The more necessary training the families receive, the more skilled and capable of parenting they will become to manage their children's behavior.

The result of this study is congruent with the study which showed the negative self-concept of children with learning disabilities caused by anger levels and inappropriate childrearing styles of their mothers [12]. Also, it is in harmony with another research based on the effects of parental training programs for improving children's social behavior and reducing social conflict [13]. This study correspondingly is in agreement with findings of a research that showed the effects of the parents' group training with ADHD children in reducing children aggressive behaviors, parents' stress and parents' behavioral improvement [14]. Similarly, it is in harmony with another research that showed parent management training can be an effective method to treat the external symptoms of children with ADHD [15].

It is important to pay attention to the characteristics and positive aspects of children's behavior rather than focusing on their negative aspects. Children need to be armed with a positive and healthy attitude to find their way in their lives. When they have a positive evaluation of themselves, others and life, they feel a higher sense of value. This issue is of greater importance for children with ADHD. Management skills training to the parents results in considering children positive traits, abilities, beauties and special talents. Several controlled clinical trials also have presented pieces of evidence in favor of the effectiveness of family behavioral interventions to prevent and treat a range of behavioral and emotional problems in children. This disorder makes children alienated from the society, symptoms sometimes may persist into adulthood and the 
person suffering from this disorder can make irrecoverable damage to oneself, family and society. So, it requires that parent management skill training be given special attention as a practical and effective therapy.

\section{Acknowledgments}

We appreciate all of the mothers and their children who made doing this research possible.

\section{Footnote}

Authors' Contribution: All authors had an equal role in the design, work, statistical analysis and manuscript writing.

\section{References}

1. Lerner JW. Learning disabilities: Theories, diagnosis, and teaching strategies. Houghton Mifflin Harcourt (HMH); 1989.

2. Tehranidoost M, Shahrivar Z, Moharreri F, Gharaei JM. Efficacy of the Positive Parenting Program (Triple-P) for a Group of Parents of Children with Attention Deficit Hyperactivity Disorder (ADHD). Iran J Psychiatr. 2008;3(2):59-63.

3. Resnick RJ. Attention deficit hyperactivity disorder in teens and adults: they don't all outgrow it. JClin Psychol. 2005;61(5):529-33. doi: 10.1002/jclp.20117. [PubMed: 15723420].

4. Binsinger C, Laure P, Ambard MF. Regular extra curricular sports practice does not prevent moderate or severe variations in self-esteem or trait anxiety in early adolescents. J Sports Sci Med. 2006;5(1):123.
5. Jafari BS, Mosavi R, Fathi Ashtiani A, Khoshabi K. The effectiveness of positive parenting program on the mental health of mothers with children suffering from attention deficit/hyperactivity disorder.JFam Res. 2011;6(4):497-510.

6. Zargarinezhad GH, Yekeh Yazdandoust R. Efficacy of parent's training on problem behaviors in ADHD children. J Psychol Stud. 2007;3(2):2948.

7. Sanders MR. Parenting interventions and the prevention of serious mental health problems in children. Med J Aust. 2002;177(7):S87. .

8. Azadbakht L, Esmaillzadeh A. Dietary patterns and attention deficit hyperactivity disorder among Iranian children. Nutrition. 2012;28(3):242-9.

9. Coopersmith S. The antecedents of self-esteem. Consulting Psychologists Pr; 1967.

10. Ostadian M, Soodani M, Mehrabizadeh Honarmand M. The effect of group counseling manner rational-emotional-behavioral on selfesteem on third grade middle school female students in Behbahan city] persian.J Counsel Res Dev. 2010;9(33):107-24.

11. Sprafkin J, Mattison RE, Gadow KD, Schneider J, Lavigne JV. A brief DSM-IV-referenced teacher rating scale for monitoring behavioral improvement in ADHD and co-occurring symptoms. J Atten Disord. 2011;15(3):235-45. doi: 10.1177/1087054709360655. [PubMed: 20228218].

12. Danesh E, Manavi SHAD M, Khoushabi K, Tavakoli M. The impact anger level and childrearing styles of mothers on self-concept of their children with or without LD. J Fam Res. 2014;10(2):175-96.

13. DeRosier ME, Gilliom M. Effectiveness of a parent training program for improving children's social behavior. J Child Fam Stud. 2007;16(5):660-70.

14. Danforth JS, Harvey E, Ulaszek WR, McKee TE. The outcome of group parent training for families of children with attention-deficit hyperactivity disorder and defiant/aggressive behavior. J Behav Ther Exp Psychiatry. 2006;37(3):188-205. doi: 10.1016/j.jbtep.2005.05.009. [PubMed: 16112077].

15. Arabi S, Danesh E, Kakavand AR, Saliminia AR, Amirghafari M. Efficacy of Parent Management Training on Reducing Symptoms of External Disturbances in Children with Attention Deficit/Hyperactivity. J Alborz Health. 2013;2(3):139-46. 